\title{
O MIEIB e a política da educação infantil
}

Karla Wanessa Carvalho de Almeida Faculdade de Formação de Professores da Mata Sul (Brasil) Cibele Maria Lima Rodrigues Fundação Joaquim Nabuco (Brasil)

\section{Resumo}

Movimento Interfóruns de Educação Infantil do Brasil contribuiu para a construção da política da educação infantil e, para essa análise, recorre-se à concepção de relação agonística, permeada pela lógica da hegemonia, na perspectiva de Mouffe, Laclau e Southwell. Utiliza-se no trabalho a análise documental e entrevistas semiestruturadas com lideranças do movimento. As análises indicaram o MIEIB como uma articulação entre lutas por creches e a atuação de intelectuais orgânicas. $\bigcirc$ espectro de sua contribuição nos sentidos, presentes nas políticas de educação infantil, é vasto. $O$ movimento empreendido para a inclusão das creches no Fundo de Manutenção e Desenvolvimento da Educação Básica e de Valorização dos Profissionais da Educação e a revisão das Diretrizes Curriculares Nacionais para a Educação Infantil são referências de atuação nas políticas. $O$ MIEIB defendeu especificidades no currículo na infância, que também se fizeram pressentes nas primeiras versões da Base Nacional Comum Curricular. Com a mudança de governo, a participação do MIEIB se restringiu.

Palavras-chave: Movimento Interfóruns de Educação Infantil do Brasil. Currículo. Educação infantil. Política educacional.

\section{MiEIB and children education policy}

\section{Abstract}

The Inter-Forum Movement for Children Education in Brazil (MIEIB) contributed to the construction of the children education policy and, for this analysis, we have turned to the concept of an agonistic relationship, permeated by the logic of hegemony, in the perspective of Mouffe, Laclau and Southwell. Document analysis and semi-structured interviews with leaders of the movement are used in the work. The analyzes indicated MIEIB as an articulation between struggles for nurseries and the performance of organic intellectuals. The spectrum of their contribution in the directions, present in children education policies, is wide. The movement undertaken for the inclusion of nurseries in the Maintenance and Development for Basic Education and Valorization of Education Professionals Fund and the revision of the National Curriculum Guidelines for Children Education. MIEIB defended specificities in the childhood curriculum, which were also present in the first versions of the National Common Curricular Base. With the change of government, MIEIB's participation was restricted.

Keywords: Inter-forum Movement of Children Education in Brazil, Curriculum. Children education. Educational policy. 


\section{MIEIB y política sobre educación infantil}

\section{Resumen}

El Movimiento Inter-Foro para la Educación de la Primera Infancia en Brasil contribuyó a la construcción de la política de educación de la primera infancia y, para este análisis, se utiliza el concepto de una relación agonista, impregnada por la lógica de la hegemonía, en la perspectiva de Mouffe, Laclau y Southwell. Se utilizan en el trabajo el análisis de documentos y entrevistas semiestructuradas con líderes del movimiento. Los análisis indicaron a MIEIB como una articulación entre las luchas por las guarderías y el desempeño de las intelectuales orgánicas. El espectro de su contribución en las direcciones presentes en las políticas de educación de la primera infancia es amplio. El movimiento emprendido para incluir guarderías en el Fondo de Mantenimiento y Desarrollo para la Educación Básica y para la Valorización de los Profesionales de la Educación y la revisión de las Directrices Curriculares Nacionales para la Educación de la Primera Infancia son referencias para la acción en las políticas. MIEIB defendió las especificidades en el plan de estudios en la primera infancia, que también estaban presentes en las primeras versiones del Currículo Nacional de Base Común. Con el cambio de gobierno, la participación de MIEIB se restringió.

Palabra-claves: Racionalidad neoliberal. Formación. Común. Praxis instituyente.

\section{Introdução}

O Estado brasileiro passou, recentemente, por um período ímpar de participação dos movimentos sociais na construção de políticas sociais. Essa inserção se deu de forma ambígua, mas bem-vinda, porque se comemora a abertura ao debate de diversas posições políticas, em um contexto de democracia e hegemonia capitalista. Os anos do Partido dos Trabalhadores no poder foram marcados pela criação de diversas arenas de disputas, nas quais foi possível estabelecer consensos provisórios, e, mesmo com limites e precariedade, foi possível fixar sentidos que tomaram forma em políticas (textos, legislações, formações). Muitas reivindicações de movimentos sociais foram atendidas dentro de uma lógica hegemônica de negociação com os interesses das classes dominantes, em um modelo próximo ao que foi denominado por Chantal Mouffe (2005) como agonístico de democracia, uma luta entre adversários no lugar de inimigos. Esse modelo teve seu fim com a saída do PT do governo e demonstra sua instabilidade.

No âmbito das políitcas educacionais muitas foram às ações concretas decorrentes de reivindicações de grupos e movimentos, mas, como em toda relação de hegemonia, muitos elementos foram excluídos. No âmbito das lutas 
sociais em torno dos direitos das crianças, tem destaque o MIEIB (Movimento Interfóruns de Educação Infantil do Brasil), como sujeito político par excellence. $E$, desde seu surgimento, tem sido protagonista na cena da educação infantil, estabelecendo consensos em meio à sua heterogeneidade. $O$ marco do seu surgimento é uma reunião realizada durante o evento da Associação Nacional de Pós-Graduação e Pesquisa em Educação - Anped em Caxambu-Minas Gerais, em 1999. Era uma época que motivava a organização, em pleno governo Fernando Henrique, auge dos tempos neoliberais.

Embora se trate de um ambiente acadêmico, o surgimento também é marcado pelas lutas dos movimentos populares, lutas das mulheres por creches e por melhores condições de vida. De um lado, o ethos acadêmico que vincula - MIEIB ao mundo das pesquisas no campo das infâncias e, de outro lado, os vínculos com as lutas populares e um campo ético-político de lutas por direitos, tal como definido por Ana Maria Doimo (1993). Essa articulação política não elimina as diferenças das tensões internas e também traduz o esforço de uma luta comum, ou como diria Laclau, de construção de um ponto nodal, em favor dos direitos das crianças pequenas.

Partindo desse contexto, o presente artigo tem por objetivo apresen3 tar, em linhas gerais, a atuação recente do MIEIB na política da educação infantil, sobretudo nas últimas décadas. Essa atuação será analisada a partir da lógica da hegemonia, postulada por Laclau e Mouffe (2015) e, seguindo essa abordagem, a análise das políticas educacionais de Myriam Southwell (2007, 2008, 2012). Argumentamos que a forma democrática (agonística) que predominou no governo Lula, sobretudo, a partir de 2007, propiciou a participação efetiva do MIEIB na construção dessas políticas. Para compreender essa atuação, a primeira parte do texto trata do referencial teórico, em linhas gerais, para explicar os termos específicos empregados na abordagem. Na segunda parte, tem-se um breve histórico do MIEIB, que permitirá compreender melhor a sua influência nos textos de política curricular, assunto que será objeto do trecho seguinte.

\section{Procedimentos Metodológicos}

Dardot e Laval (2016) constatam que o neoliberalismo transformou em profundiA pesquisa tem natureza qualitativa (MINAYO, 2009) considera 
contingência, linguagem e sujeito como elementos que, imbricados e contextualizados, podem fornecer possibilidades de compreensão da realidade social. Nesse sentido, as subjetividades das participantes tecem uma história, que ressaltam relações, contradições, efeitos do poder, interesses na construção da política de educação. Para tanto, utilizou-se análise documental, entrevistas semiestruturadas com lideranças e observação participante nos encontros do movimento. $O$ corpus foi composto pelos documentos do Movimento: as Cartas dos Encontros Nacionais do MIEIB e informações disponíveis em seu site, além dos documentos normativos: Diretrizes Curriculares Nacionais para a Educação Infantil e Base Nacional Comum Curricular. Foram realizadas seis entrevistas com lideranças do MIEIB.

\section{Política, Discursos e Hegemonia}

A política educacional é compreendida como prática discursiva e campo de luta de poder. $O$ poder de nomeação, de definição das "diretrizes", da "legislação" (LACLAU, 2011; 2013) do que será considerado racional e legítimo. $\bigcirc$ discurso que permeia os textos oficiais llegislações e orientações normativas) de uma política específica representa a forma como a hegemonia busca campos de equivalências e flutuações a fim de "introduzir interseccionalmente" o que julga necessário. É o discurso em um contexto de hegemonia. A hegemonia, nessa perspectiva, está relacionada com o jogo da articulação das diferentes demandas. Laclau e Mouffe apresentam a prática articulatória para explicar como ocorre esse processo:

[...] chamaremos de articulação qualquer prática que estabeleça a relação entre elementos tal que suas identidades sejam modificadas como um resultado da prática articulatória. À totalidade estruturada resultante da prática articulatória, nós chamaremos de discurso. As posições diferenciais na medida em que elas aparecem articuladas dentro do discurso, nós chamaremos de momentos. Por contraste, nós chamaremos elementos qualquer diferença que não seja discursivamente articulada (LACLAU; MOUFFE 2015, p. 178).

discurso é uma aparente "totalidade", repleta de falhas e contradições, resultante de uma prática articulatória que fixa (precariamente) os sentidos. E deixam outras diferenças excluídas, o que chamam de "elemento". 
O MIEIB e a política da educação infantil

As posições diferenciais na medida em que aparecem - o que os autores chamam de momentos. Essas diferenças podem ser articuladas em ações coletivas ou movimentos sociais. Por essa razão, as lutas dos movimentos sociais são também lutas por significação (ALVAREZ, DAGNINO, ESCOBAR, 2000; GOHN, 2005).

Os movimentos emergem quando conseguem a adesão de pessoas em torno de um ponto comum (ponto nodal), uma bandeira de luta, nas palavras da "militância". Na perspectiva de Laclau e Mouffe (2015), pontos nodais são significantes privilegiados que fixam (parcialmente) um sentido, conferindo uma aparente coesão ao grupo. Aquele ponto de convergência vai se desenvolvendo em uma cadeia de equivalência para ampliar a adesão - lutas equivalentes que são agregadas. Nesse sentido, também os movimentos constituem seu discurso a partir de uma demanda particular.

No Brasil, a partir do contexto da Constituinte de 1988, a atuação dos movimentos se volta para a construção das políticas e de formas de participação nas políticas, sobretudo por meio da criação de conselhos e conferências nacionais. As lutas sociais tomaram como ponto de convergência a defesa do direito a ter direitos (TELLES, 2006) em uma sociedade hegemônica

5 autoritária - e, por essa razão, desigual e hierarquizada -, na qual os direitos sociais não são totalmente reconhecidos como legítimos.

Em alguns momentos (conjunturas), os movimentos sociais conseguem se articular e traduzir sua agenda em políticas públicas, mas suas reivindicações também atuam na redefinição das noções de democracia, de participação, cidadania e representação política. A atuação dos movimentos pode oscilar, como definiu Mutzenberg (2002), pois nem sempre constroem o "novo". Suas manifestações coletivas podem ter pelo menos três "formas": momentos de adesão à configuração hegemônica sedimentada; manifestações de conflito, no interior de uma lógica hegemônica (relativas aos processos decisórios e operacionais); manifestações de posições antagônicas (quando os sentidos fixados são negados e novos sentidos são propostos). Na perspectiva defendida por Mouffe (2005), a democracia ideal seria uma arena agonística na qual as diferenças não seriam anuladas, mas tratadas como projetos de adversários em disputa, "[...] constituindo-se mecanismos institucionais que visem principalmente 'domesticar' as relações antagônicas entre identidades que visam hegemonizar sentidos no espaço social, visto pela autora como um espaço discursivo" (MENDONÇA, 2010, p. 491). Essa arena agonística foi vivenciada 
pelos movimentos nos governos do Partido dos Trabalhadores, muito mais no governo Lula, sob a hegemonia do sistema capitalista. Essa arena vinha sendo instituída no momento da Constituinte por meio de diversos fóruns que atuaram como redes movimentalistas nas lutas pelo direito a ter direitos.

\section{MIEIB: uma prática articulatória em torno da Educação Infantil}

No campo do direito à educação muitas foram as lutas que resultaram em legislações como a Lei de Diretrizes e Bases da Educação Nacional 9.394/96. Um elemento historicamente excluído das políticas educacionais era a educação infantil, primeiro traduzida na luta populares por creches, depois reconhecida como parte constitutiva do processo educativo das crianças.

MIEIB surge no seio dessa configuração discursiva e aglutina esses elementos e sujeitos de uma forma singular. Sua história se inscreve na trajetória dos fóruns criados no Brasil, no entanto, emergiu no contexto pós-Constituinte, em 1999. Foi impulsionado principalmente com a criação da Comissão Nacional de Educação Infantil, a partir do trabalho das equipes "[...] do Instituto de Recursos Humanos João Pinheiro, sediado em Belo Horizonte; das Delegacias do MEC (DEMEC), em Minas Gerais e no Rio de Janeiro" (MIEIB, 2019). Também é fruto das lutas empreendidas no campo educacional ao longo da Constituinte e da LDB que resultaram no reconhecimento da educação infantil na LDB 9.394/96 (MIEIB, 2002).

MIEIB organiza-se em um formato peculiar de rede de redes, uma rede de fóruns. Nesse desenho, cada fórum participante mantém uma organização peculiar, "[...] definidos como instâncias autônomas de articulação interinstitucional e suprapartidária" (ARELARO; MAUDONNET, 2017). No entanto, existe um grupo gestor e uma secretaria executiva que, de alguma forma, garante a centralidade de alguns processos organizativos (MIEIB, 2002). Essa prática articulatória constitue um discurso comum, sem eliminar as diferenças internas. Nesse sentido, os fóruns estaduais têm uma atuação própria (MIEIB, 2019). O grupo que compõe o MIEIB optou pela não institucionalização jurídica do movimento, para preservar seu caráter de movimento social (MIEIB, 2002). Portanto, O MIEIB se consiste em uma rede de redes - articulando instituições parceiras eventuais ou efetivas, que oferecem algum tipo de suporte às atividades do movimento (MIEIB, 2002). 
O MIEIB e a política da educação infantil

A criação de um movimento necessita de uma vontade coletiva que seja traduzida pelo aumento de adesões. $\bigcirc$ texto do MIEIB trata essa ampliação da sua base a partir de uma "[...] atuação consistente e multiplicadora" (MIEIB, 2002, p. 16). Como todo movimento, o MIEIB é heterogêneo e é composto por professores da educação infantil pública e privada, coordenadores e diretores de instituições de ensino, pesquisadores e instituições de pesquisa, órgãos governamentais, conselhos de educação, de assistência social, de justiça e de saúde, ONGs, comunidades, sindicatos, dentre outros. Criou espaços de encontros locais, regionais e nacionais para debates específicos da agenda da política nacional de educação infantil. Segundo Flores (2016), os fóruns possuem capilaridade comunicativa no uso das Tecnologias da Informação e da Comunicação - TIC: grupos de discussão, o mailing, blogs e sites e grupos no Facebook, WhatsApp e Skype.

Os consensos construídos ao longo de sua existência estão expressos em um livro (Educação infantil: construindo o presente) e em seu site. As três dimensões elencadas traduzem a sua "identidade" e a forma como foi construída essa prática articulatória, em torno de luta por direitos, com atuação de pesquisadoras e com a constituição de uma vontade geral em torno da 7 necessidade de atuação nas políticas. Sendo assim, a primeira dimensão é a da legislação, já defendida desde o processo da Constituinte, que continua como bandeira de luta, sobretudo no âmbito de cumprimento do que já existe (direito a ter direitos). Quando os movimentos levam à aprovação de leis criam um parâmetro de racionalidade importante num contexto conservador. A lei é o apelo para a racionalidade da demanda, tornando-a justa e evidente (RANCIÈRE, 1996). Por outro lado, cria uma arena de disputa em torno dos sentidos, na qual muitas vezes os sujeitos usam as mesmas palavras com sentidos diferentes.

Rancière (1996) defende que no seio de toda argumentação e de todo litígio argumentativo político, existe um antagonismo primeiro que incide sobre o entendimento da linguagem, gerando o desentendimento, a disputa sobre o sentido a ser dado a uma palavra na cena política. Nessa perspectiva, todo movimento social é fruto desse desentendimento ao apontar outro sentido para uma mesma "coisa". O movimento coloca em cena a racionalidade e a legitimidade de suas reivindicações. Nesse sentido, o MIEIB tem a peculiaridade de utilizar como segunda dimensão a racionalidade científica, por meio de suas intelectuais orgânicas que aliam militância, teoria e evidências 
empíricas, realizando pesquisas como forma de evidenciar e tornar racional o argumento, como diria Rancière (1996). A partir dessa racionalidade hegemônica, o movimento constitui os argumentos contrários ao discurso dominante. O MIEIB busca influenciar na prática para concretizar essa construção teórica. Assim, a terceira dimensão tem foco na gestão e visa influenciar as práticas nas instituições educacionais (MIEIB, 2002). Todo esse conjunto de práticas discursivas em torno do direito à educação das crianças de $\mathrm{O}$ a 6 anos.

Ao analisarmos os documentos disponibilizados no site, encontramos um histórico processo de produção de conhecimento (dimensão educadora), incluindo mudanças ao longo do tempo. Essa produção se concretiza em seminários, colóquios, grupos de estudos e debates em torno dos significantes infâncias, além da política, educação e identidade profissional do educador de educação infantil, agregando uma gama de intelectuais orgânicos de todas as regiões brasileiras. Assim, o discurso se constitui com fundamentações políticas e epistemológicas, com interlocuções diretas, com os avanços das pesquisas nos campos da sociologia e antropologia da infância e psicologia. Vale ressaltar que essa atuação é relevante no campo acadêmico. $\bigcirc$ MIEIB nasceu na reunião da Anped, em 1999, e sua articulação se mantém no campo da atuação da pesquisa, sobretudo no GT 7, que trata da educação das crianças de $\mathrm{O}$ a 6 anos.

\section{Contribuições para as Políticas de educação infantil}

Entre 1999 e 2003, o MIEIB teve uma atuação que pode ser denominada de caráter reivindicatório e antagônico ao "governo" de Fernando Henrique Cardoso. Um governo que não estabeleceu diálogos com os movimentos sociais e consolidou as reformas neoliberais que já estavam em curso. A exclusão da educação infantil do Fundo de Manutenção e Desenvolvimento do Ensino Fundamental é a prova cabal do não reconhecimento da educação infantil como direito.

Nas eleições de 2002, o movimento enviou cartas compromisso com a educação infantil aos presidenciáveis. Em resposta, Luís Inácio Lula da Silva se compromete em reconhecê-lo como um sujeito político interlocutor junto ao Ministério da Educação na formulação da política de educação infantil, e ainda em apoiar suas ações e incluílo como representação nas discussões da transição e definição das políticas. Essa promessa é efetivada por Lula 
O MIEIB e a política da educação infantil

e esse "status" fomenta o início da relação entre MIEIB e governos do PT, em uma relação "agonística", em certo sentido. A primeira iniciativa do governo (FARIA, 2005) foi a criação do Conselho de Políticas para a Educação Básical (CONPEB), no segundo semestre de 2003, do qual o MIEIB passou a integrar.

O MIEIB passou a fazer parte Foram de diversas as instâncias do governo. Em termos curriculares, o MIEIB atua em uma articulação com diferentes movimentos sociais para a constituição de um currículo que respeitasse as especificidades das infâncias, considerando a diversidade cultural e as lutas dos movimentos na educação para promoção da igualdade racial e na educação do campo ${ }^{2}$. Essa interação também provoca mudanças no próprio movimento como afirmaram as entrevistadas. É verdade que as discussões aconteciam nos fóruns estaduais, principalmente pelo fato da oferta educacional no campo ser menor, em termos percentuais (VIEIRA, 2010).

Nesse bojo, concebemos que a revisão das Diretrizes Curriculares Nacionais para a Educação Infantil - DCNE), constituiu-se um momento chave para materializar em políticas demandas e concepções defendidas pelo MIEIB e suas intelectuais orgânicas (quase todas mulheres), bem como por diversos especialistas em educação infantil. Nesse sentido, exerceram 9 o que Laclau denominou de prática articulatória, incluindo os sentidos no texto da política. No caso das DCNEls, participaram a União Nacional dos Conselhos Municipais de Educação - UNDIME, a Associação Nacional de Pós-Graduação e Pesquisa em Educação - Anped, a Confederação Nacional dos Trabalhadores em Educação - CNTE, o Fórum Nacional de Conselhos Estaduais de Educação, o Movimento Interfóruns de Educação Infantil do Brasil - MIEIB, a Secretária de Educação Básica - SEB, a Secretária de Educação Continuada Alfabetização, Diversidade e Inclusã - SECADI, além de especialistas e uma consultora da área de educação infantil. Nesse contexto de democracia agonística, existiram divergências entre aqueles que se aproximaram do campo-ético político das lutas por direitos e por justiça social e outros com argumentos neoliberais. Todos se aglutinaram para formar um texto final, por um processo de identificação, sem, contudo, apagar os traços antagônicos entre si, o que Laclau (201 1) denomina de plenitude ausente.

Nesse contexto, o discurso do MIEIB inclui os sentidos em torno da construção de criança como "[...] sujeito biopsicossocial, produtora de história, de cultura, capaz de aprender, de intervir e modificar a realidade de maneira espontânea, lúdica, criativa e estética" (MIEIB, 2012, p. 2). Esse enunciado tem 
por referência os estudos da sociologia da infância e educação infantil como primeira etapa da educação básica, em espaços institucionais não domésticos, mas públicos e privados, que cuidam e educam as crianças de $\mathrm{O}$ a 5 anos em período diurno parcial ou integral.

No contexto da produção do texto, encontram-se o Conselho Nacional de Educação (CNE), responsável pela sistematização do texto e que buscou a partir de um texto síntese, debatido em audiências públicas nacionais, incorporar contribuições de diversos grupos e entidades como a Organização Mundial para a Educação Pré-escolar (OMEP) e Universidades Federais. O processo de sistematização escrita do texto comportou diversos discursos e os sentidos construídos correspondem à dinâmica de associação que Laclau (2011) denomina de momento, e ocorre por uma articulação política. $\bigcirc$ documento, portanto, é o produto dessa prática, na qual se busca equivalências - o contorno específico do potencial de mudança que se tornou hegemônico pelo esvaziamento de um significante.

No caso das DCNEls um ponto nodal é a criança. Vejamos como as construções de sentidos são provisórias e dependem das articulações dos sujeitos políticos envolvidos nas práticas articulatórias. Nas DCNEls de 1999 a criança comporta o sentido de "[...] seres íntegros, que aprendem a ser e conviver consigo próprios, com os demais e o próprio ambiente de maneira articulada e gradual [...]" (BRASIL, 1999, p. 1). Contingencialmente, a partir de influências de sujeitos políticos, formam-se uma nova estrutura enunciativa para a criança nas DCNEls de 2009: "[... sujeito histórico e de direitos que, nas interações, relações e práticas cotidianas que vivencia, constrói sua identidade pessoal e coletiva, produzindo cultura" (BRASIL, 2010, p. 12).

Notemos como essas construções expõem as marcas hegemônicas do contexto sociopolítico do momento histórico do qual são produtos. Na primeira, há uma formação genérica que subliminarmente vincula uma visão dicotômica entre cuidar e educar. Na segunda, entretanto, temos a dimensão histórica na qual podemos indicar singularidades dos contextos socioculturais, socioeconômicos e étnicos. Na dimensão do direito, localiza o comprometimento social e político do Estado em sua responsabilidade na educação coletiva das crianças. Ao destacar as vivências e construções realizadas no plano pessoal e coletivo, o enunciado abarca sentidos que se voltam às múltiplas formas de ser criança, além dos traços de um ciclo de desenvolvimento, isso implica no reconhecimento da potencialidade da criança. 
O MIEIB e a política da educação infantil

Vale enfatizar, portanto, que esse novo sentido presente nas DCNEIs (2009) aproxima-se do discurso do MIEIB (MIEIB, 2012), levando-nos a crer que este foi sujeito hegemônico (por hegemônico compreendemos, não a ausência de outros sujeitos nesse processo, mas o sujeito com maior capacidade de articular e atribuir sentidos aos discursos presente no texto das políticas), como resultado da confluência das vozes presentes:

[...] de toda uma luta também pela construção essa concepção de uma concepção de educação infantil. Então quando a gente olha para as diretrizes curriculares nacionais de 2009, que são uma revisão das de 99, a gente ver a influência muito grande desse movimento, que é o Movimento Interfóruns de Educação Infantil do Brasil (P4, 2018).

Outro elemento no enunciado das DCNEls (2009) que apoia nossa afirmação pode ser indicado quando se ressalta o caráter não doméstico da educação infantil, enfatizando o "[...] caráter institucional e educacional" (BRASIL, 2010, p. 84).

As creches e pré-escolas se constituem, portanto, em estabelecimentos educacionais públicos ou privados que educam e cuidam de crianças de zero a cinco anos de idade por meio de profissionais com a formação específica legalmente determinada, a habilitação para o magistério superior ou médio, refutando assim funções de caráter meramente assistencialista, embora mantenha a obrigação de assistir às necessidades básicas de todas as crianças (BRASIL, 2010, p. 84).

Essa concepção antagoniza as propostas de "homeschooling" ou escola em casa que estão em voga no governo atual. $\bigcirc$ pressuposto do MIEIB está calcado no estado de direito que constrói políticas sociais para, de alguma forma, amenizar as contradições do capitalismo, como diria Marx. Por essa razão, argumentamos que se trata da busca da república - que não foi consolidada e que novamente está ameaçada no contexto atual, de aparente democracia - em colocar os adversários como inimigos (invertendo a lógica agonística proposta por Mouffe).

Naquele contexto agonístico, o MIEIB insere nas DCNEls (2009) o vínculo entre infância e educação infantil que se realiza pelos significantes integração e desenvolvimento, apresentando como objetivo da educação infantil 
o "[...] desenvolvimento integral em seus aspectos físico, afetivo, psicológico, intelectual e social, complementando a ação da família e da comunidade" (BRASIL, 2010, p. 36). $\bigcirc$ enunciado presente no documento se assemelha àquele das cartas dos encontros nacionais do movimento: "[...] sujeito biopsicossoacial, produtora de história, de cultura, capaz de aprender, de intervir e modificar a realidade de maneira espontânea, lúdica, criativa e estética" (MIEIB, 2009, p. 2).

Os sentidos comuns e equivalentes fazem emergir uma superfície de inscrição de significantes flutuantes na concepção de currículo, principalmente inspirado na quebra com as subalternidades da criança pelo adulto, em outras palavras, a "[...] vivência da infância e novas formas de sociabilidade e de subjetividades comprometidas com a democracia e a cidadania, [...], e com o rompimento de relações de dominação etária [...]" (BRASIL, 2010, p. 85). O discurso se equivale com o rompimento com a normatividade de escolarização e atua como possibilidade de respeito às especificidades da infância em suas temporalidades, "[...] espaços privilegiados de convivência, de construção de identidades coletivas e de ampliação de saberes e conhecimentos de diferentes naturezas" (BRASIL, 2010, p. 85).

Nesse sentido, as DCNEls (1999 e 2009) propõem atividades intencionais, subdivididas em momentos de ações: estruturadas, espontâneas e livres, integrando as diversas áreas de conhecimento e aspectos da vida cidadã, próximas de uma dimensão curricular como:

[...] um conjunto de práticas que buscam articular as experiências e os saberes das crianças com os conhecimentos que fazem parte do patrimônio cultural, artístico, científico e tecnológico. Tais práticas são efetivadas por meio de relações sociais que as crianças desde bem pequenas estabelecem com os professores e as outras crianças, e afetam a construção de suas identidades (BRASIL, 2010, p. 86).

As realidades das crianças que neste domínio são levadas em consideração no fazer pedagógico da educação infantil são "[...] intencionalmente planejada e permanentemente avaliada" (BRASIL, 2010, p. 86), resultando na centralidade da criança. A ação vem adjetivada como mediadora, norteada pelos eixos interações e brincadeira. 
[...] as crianças devem ser mediadas na construção de uma visão de mundo e de conhecimento como elementos plurais, formar atitudes de solidariedade e aprender a identificar e combater preconceitos que incidem sobre as diferentes formas dos seres humanos se constituírem enquanto pessoas (BRASIL, 2013, p. 87).

Assim posto, a inclusão da Educação do Campo (Resolução CNE/ CEB n ${ }^{0} 2$, de 28 de abril de 2008) atua como inscrição de significantes e opera na lógica da diferença. Essa normativa dispõe que a educação infantil e os anos iniciais do ensino fundamental serão sempre oferecidos nas próprias comunidades rurais, evitando-se os processos de nucleação de escolas e de deslocamento das crianças (BRASIL, 2008) - uma reivindicação dos movimentos do campo. E ainda se articula com as lutas dos povos indígenas na escolha dos modos de educação de suas crianças de $\mathrm{O}$ a 5 anos de idade - uma demanda dos movimentos indígenas.

Essa nova forma de enunciação (flutuante) incorpora o debate público feito ao longo da formulação do texto e assim incorpora demandas de diversos movimentos sociais formados por educadores, bem como no reconhecimento das infâncias do campo, no sentido de considerar espaços/tempos nunca

13 antes percebidos nas políticas na história do Brasil. As vozes das lutas populares tiveram espaço e foram expressos no documento.

Em uma sociedade cartorial como a nossa, a existência de um documento não significa sua aplicação. Para Canavieira (2018), o MIEIB não cobrou uma formação específica para a operacionalização das DCNEls. No entanto, encontramos na Carta de Balneário de Camboriú (2009) uma reivindicação ao MEC para que fossem elaborados documentos complementares com orientação para a implementação das DCNEls, bem como estratégias para sua formação. Canavieira (2018) acredita que o alto grau de envolvimento do MIEIB com a coordenação de educação infantil do Ministério da Educação - COEDI não possibilitou a efetivação de uma incidência acirrada. Esse pensamento, em certa medida, está presente numa parcela dos membros do movimento que entrevistamos.

Acho que o fato da gente contar também com o governo, que mesmo a gente tendo recusas e críticas era um governo do nosso lado Então eu acho que o MIEIB talvez, e aí a gente tem que fazer uma autoanálise, possa ter ficado um pouco arrefecido nessa 
combatividade necessária, até porque muitas das suas pautas, elas estavam presentes em termos de políticas públicas (P4, 2018).

Mesmo com limites, o governo Luís Inácio Lula da Silva deu voz aos movimentos e propiciou ganhos consideráveis, principalmente porque possibilitou reconhecimento das demandas como legítimas e permitiu ao movimento sedimentar essas concepções em praticamente todos os documentos orientadores e normativos da COEDI. Uma análise que fizemos das publicações da COEDI nesse período corrobora nossa afirmação. Mesmo que o MIEIB não apareça como elemento colaborador, as publicações contam com a participação de intelectuais orgânicas do movimento em reuniões de trabalho organizadas pela COEDI-MEC (Ângela M. Rabelo F. Barreto, Lívia Maria Fraga Vieira, Rita de Cássia de Freitas Coelho, Tizuko M. Kishimoto, Zilma de Moraes Ramos de Oliveira e outras). Ou mesmo as assessorias de Maria Luiza Flores e Simone Albuquerque (Fórum Gaúcho), Marlene Oliveira (Fórum Baiano), Monica Baptista (Fórum Mineiro), Ângela Scalabrim (Fórum Paranaense), Fernanda Leal (Fórum Paraíba) e Jaqueline Pasuch (Fórum do Mato Grosso) (MAUDONNET, 2019).

Esses sentidos também estão presentes no contexto de produção da BNCC. O discurso da necessidade de uma Base vinha sendo alimentado no Ministério da Educação desde 2009, com o Programa Currículo em Movimento (BRASIL, 2009), que ganhou força em 2014 com a aprovação do Plano Nacional de Educação Lei n 13.005/14, 2015, embasados na sua previsão na Constituição de 1988, nos artigos 205 e 210, na Lei de Diretrizes e Bases (1996), no artigo 9 inciso VI, e nas Diretrizes Curriculares Nacionais (2013). No entanto, na conjuntura do país em 2015, de forte inclinação à privatização e ao reformismo educacional, apresentava-se mais como um perigo (MAUDONNET, 2019) do que terreno estratégico educacional para "eliminar" as desigualdades do ensino brasileiro, atuando como um "parâmetro obrigatório do desenvolvimento integral dos cidadãos" (BRASIL, 2017).

A partir do interdiscurso, suas primeiras versões apresentam-se como uma construção coletiva com participação efetiva de intelectuais do MIEIB, através de eventos como seminários, consultas públicas e relatórios analíticos, pareceres de leitores críticos, associações científicas e professores pesquisadores das universidades, externos ao comitê de assessores e especialistas. No processo de construção da BNCC, houve divergências internas no MIEIB. Enquanto a COEDI aderiu à sua sistematização, algumas questionavam o papel 
O MIEIB e a política da educação infantil

do MIEIB na produção de uma política que oferecia elementos para uma padronização pedagógica e de avaliação, abrindo espaço para a produção de material didático apostilado e formação continuada tecnicista (MAUDONNET, 2019 ). Esse aspecto também surgiu em nossa pesquisa, na fala de uma das entrevistadas: "[...] outra coisa muito gritante é que a escolarização da criança [...] se preocupa muito com a adoção de livros didáticos para a educação infantil. [...]" (MAUDONNET, p. 3, 2018), elemento que descaracteriza a identidade política da educação infantil e suas acepções de criança e infância. Entre os dissensos provocados pela BNCC-El no interior do MIEIB, notamos que a produção do discurso contido nas duas primeiras versões (que contavam com intelectuais do MIEIB entre os sujeitos políticos) buscou organizar e redistribuir o lugar da criança e das infâncias em suas aprendizagens e desenvolvimento.

Com os acontecimentos iniciados em 2015, uma crise política lparlamentar), jurídica, midiática e social se instalou no Brasil. Em 2016, acontecia o processo de impeachment da presidente Dilma, com a destituição de seu governo, seu vice, Michel Temer, assume a presidência. Logo, se segue um processo de desmontes e ações de retrocessos gigantescos que realçam as marcas do colonialismo e do poder econômico. Nessa conjuntura, suas medidas são 15 inteiramente restritivas dos direitos sociais, retrógradas, que aumentam a desigualdade, secundarizam a educação, roubam seu financiamento e desmontam - Plano Nacional de Educação, promovendo uma configuração hegemônica distinta, que toma forma na versão final da BNCC. Nesta, é perceptível a falta de participação das entidades acadêmicas e movimentos sociais - ao contrário, se destacam os intelectuais de grupos empresariais. Constatamos que a BNCC tem sido considerada, nos termos de Laclau (1990), um discurso mítico, única possibilidade possível, no nosso caso, de solução e resolução de dado problema educacional.

\section{Considerações finais}

Nos textos das políticas, a partir da colaboração do MIEIB, encontramos sentidos que modelaram e fixaram concepções (SOUTHWELL, 200) a partir de significantes privilegiados que receberam papel articular em um dado contexto (LACLAU, 201 1, 2013; SOUTHWELL, 2012), condensando em si o significado de todo um campo antagônico. A compreensão das infâncias, que inclui as múltiplas formas de ser criança e sua educação - ou seja, 
o que apreender por educação infantil e os aspectos das condições justas de trabalho para os/as profissionais de educação infantil - formam esses blocos de sentidos, que são simultaneamente mecanismos que possibilitam a construção de um currículo a partir de experiências e vivências e de um atendimento pedagógico (onde cuidar, educar e brincar são indissociáveis) as crianças brasileiras compreendidas como seres de direitos. Nesse caso, a participação do MIEIB no jogo de construção da política permitiu incluir e aprofundar propostas e projetos coletivos advindos da realidade infantil brasileira, a partir de muitos trabalhos técnicos produzidos para o MEC.

Portanto, as contribuições do MIEIB às políticas de educação infantil, nesse artigo, foram evidenciadas a partir da construção dos sentidos e suas flutuações nos discursos políticos, descritos em práticas articulatórias. Nessas articulações, o MIEIB torna-se um interlocutor ativo, produzindo um bloco de forças geradas pela participação do MIEIB em outras redes, sobretudo a Campanha Nacional pelo Direito à Educação, Rede de Monitoramento Amiga da Criança, Rede Nacional Primeira Infância, ANPEd, dentre outras.

\section{Notas}

1 Participaram ANPED, MIEIB, CONSED, ANFOPE, CNTE, UNDIME, FORUMDIR, CONTEC, UNCME, CNE, UNESCO e UNICEF.

2 Existiu um grupo de trabalho interministerial para tratar da educação infantil no campo composto também por movimentos Sociais, dentre eles o MIEIB, MST e CONTAG. Na Secadi a CADARA, Comissão Assessora de Diversidade para Assuntos Relacionados à Educação dos Afro-Brasileiros, composta pelos movimentos negros, com presença do MIEIB.

\section{Referências}

ARELARO, Lisete Regina Gomes; JACOMINI, Márcia Aparecida; KLEIN, Sylvie Bonifácio. $\bigcirc$ ensino fundamental de nove anos e o direito à educação. Educação e Pesquisa, São Paulo, v. 37, n. 1, p. 35-51, jan./abr. 2011 . Disponível em: http://www.scielo.br/pdf/ ep/v37n1/v37n la03.pdf. Acesso em: 22 jul. 2019.

ARELARO, Lisete Regina Gomes; MAUDONNET, Janaína Vargas de Moraes. Os fóruns de educação infantil e as políticas públicas para a infância no Brasil. Laplage em Revista, Sorocaba, v. 3, n. 1, p. 6-18, 2017. Disponível em: http://www.laplageemrevista.ufscar. $\mathrm{br} /$ index.php/lpg/article/view/238. 
O MIEIB e a política da educação infantil

Acesso em: 6 ago. 2018

BRASIL. Diretrizes Curriculares Nacionais para a Educação Infantil. Conselho Nacional de Educação. Resolução CEB 1/99. Diário Oficial da União, Brasília, 1999. Disponível em: http://portal.mec.gov.br/dmdocuments/resolucao_ceb_0199.pdf. Acesso em: 22 jul. 2019.

BRASIL. Ministério da Educação. Conselho Nacional de Educação. Diretrizes complementares, normas e princípios para o desenvolvimento de políticas públicas de atendimento da Educação Básica do Campo. Resolução n², 2008. Disponível em: http://portal. mec.gov.br/index.php?option=com_docman\&view=download\&alias= 11841 -rceb00208-pdf\&category_slug=outubro-2012-pdf\&ltemid=30192. Acesso em: 22 jul. 2019.

BRASIL. Ministério Da Educação. Conselho Nacional de Educação. Revisão das Diretrizes Curriculares Nacionais para a Educação Infantil. Parecer CNE/CEB $n^{\circ} 20$ 2009. Disponível em: http://Portal.Mec.Gov.Br/Index.Php? Option=Com_ Docman\&View=Download\&Alias=3748-Parecer-Dcnei-Nov-2009\&Category_ Slug=Fevereiro-2010-Pdf\&ltemid=30192 Acesso em: 22 jul. 2019.

BRASIL. Ministério da Educação. Secretaria de Educação Básica. Diretrizes curriculares nacionais para a educação infantil. Brasília: MEC/SEB, 2010. Disponível em: https:// ndi.ufsc.br/files/2012/02/Diretrizes-Curriculares-para-a-E-I.pdf Acesso em: 22 jul. 2019.

BRASIL. Diretrizes Curriculares Nacionais para a Educação Básica. Ministério da Educação. Secretaria de Educação Básica. Diretoria de Currículos e Educação Integral. Brasília, 2013. Disponível em: http://portal.mec.gov.br/docman/julho-2013-pdf/13677-diretrizes-educacao-basica-2013-pdf/file Acesso em: 22 jul. 2019.

BRASIL. Instituto Nacional de Estudos e Pesquisas Educacionais Anísio Teixeira. Plano Nacional de Educação PNE 2014-2024: Linha de Base. Brasília: Inep, 2015. Disponível em: http://portal.inep.gov.br/documents/186968/485745/Plano+Nacional+de+E duca\%C3\%A7\%C3\%A3o+PNE+2014-2024++Linha+de+Base/c2ddOfaa-7227-40eea520-12cbfc77700féversion=1. 1. Acesso em: 22 jul. 2019.

BRASIL. Ministério da Educação. Base Nacional Comum Curricular. 2017. Disponível em: http://portal.mec.gov.br/index.php?option=com_ docman\&view=download\&alias=7960 1-anexo-texto-bncc-reexportado-pdf-2\&category_ slug=dezembro-2017-pdf\&ltemid=30192 Acesso em 3 abr. 2018.

BRASIL. Lei de Diretrizes e Bases da Educação Nacional. Brasília: Senado Federal/ Coordenação de Edições Técnicas, 2017. Disponível em: http://www.planalto.gov.br/ ccivil_03/leis/19394.htm Acesso em: 3 jan. 2018. 
CAMPOS, Maria Malta. A formação de professores para crianças de 0 a 10 anos: modelos em debate. Educação \& Sociedade, Campinas, v. 20, n. 126-142, dez. 1999. Disponível em: http://www.scielo.br/pdf/es/v20n68/a07v2068.pdf. Acesso em: 18 abr. 2017.

DAGNINO, Evelina. Cultura, cidadania e democracia: a transformação dos discursos e práticas na esquerda da América Latina. In: ALVARÉZ, S.; DAGNINO, Evelina; ESCOBAR, A. (org.). Cultura e política nos movimentos sociais latino-americanos: novas leituras. Belo Horizonte: Editora UFMG, 2000.

DOIMO, Ana Maria. Movimento popular no Brasil pós-70: formação de um campo ético-político. 1993. 212 f. Tese (Doutorado em Ciência Política) - Programa de Pós- Graduação em Ciência Política, Universidade de São Paulo, São Paulo, 1993.

FARIA, Ana Lúcia Goulart. de. Política de regulação, pesquisa e pedagogia na educação infantil, primeira etapa da educação básica. Educação e Sociedade, Campinas, v. 26, n. 92, p. $1013-1038,2005$.

FLORES, Maria Luiza Rodrigues. Incidências dos Movimentos Sociais pela garantia da Educação Infantil no Brasil. Fóruns de Educação no Brasil. In: SILVA, Otavio Henrique Ferreira da; PILOTO, Sumika Soares de Freitas Hernandez; CARA, Daniel Tojeira (org.). Rio de Janeiro: Dictio Brasil, 2016.

GOHN, Maria da Glória. O protagonismo da sociedade civil: movimentos sociais, ONGs e redes solidárias. São Paulo, Cortez, 2005.

GRAMSCl, Antonio. Os intelectuais e a organização da cultura. Tradução Carlos Nelson Coutinho. 4. ed. Rio de Janeiro: Civilização Brasileira, 1982.

GRAMSCl, Antonio. Cadernos do cárcere. Rio de Janeiro: Editora Civilização Brasileira, 2007. (v. 1)

KRAMER, Sônia. $\bigcirc$ papel social da pré-escola. Cadernos de Pesquisa, São Paulo, n. 58, p. 77-81, 1985. Disponível em: http://publicacoes.fcc.org.br/ojs/index.php/cp/ article/view/1321/1323 Acesso em: 3 abr. 2018.

LACLAU, Ernesto. Emancipação e diferença. Rio de Janeiro: EDUERJ, 2011.

LACLAU, Ernesto. A razão populista. Tradução Carlos Eugênio Marcondes de Moura. São Paulo: Três Estrelas, 2013.

LACLAU, Ernesto; MOUFFE, Chantal. Hegemonia e estratégia socialista: por uma política democrática radical. Tradução Joanildo A. Burity, Josias de Paula e Aécio Amaral. São Paulo: Intermeios; Brasília: CNPq, 2015. 
O MIEIB e a política da educação infantil

LOPES, Alice Casimiro. Discursos nas políticas de currículo. Currículo sem Fronteiras, v. 6, n. 2, p. 33-52, jul./dez. 2006. Disponível em: http://www.curriculosemfronteiras.org/ volbiss2articles/lopes.pdf. Acesso em: 15 jul. 2018.

MAUDONNET, Janaína Vargas de Moraes. Movimentos sociais em defesa da infância: os fóruns de educação infantil e suas incidências nas políticas públicas no Brasil. 2019. Tese (Doutorado) - Programa de Pós-Graduação Estado, Sociedade e Educação, Universidade de São Paulo, São Paulo, 2019.

MENDONÇA, Daniel de. Teorizando o agonismo: crítica a um modelo incompleto. Resista Sociedade e Estado, Brasília, v. 25, n. 3, p. 479-497, set./dez. 2010. Disponível em: http: / / www.scielo.br/scielo.php?.pid=S0 102-69922010000300004\&script=sci_ abstract\&tlng=pt. Acesso em: 15 jul. 2018.

MINAYO, Maria Cecília (org.). Pesquisa social: teoria, método e criatividade. Petrópolis: Vozes, 2009.

MOVIMENTO Interforuns de Educação Infantil do Brasil - MIEIB. Educação Infantil: construindo o presente. Campo Grande: Editora da UFMS, 2002.

MOVIMENTO Interfóruns de Educação Infantil do Brasil - MIEIB. Carta de Balneário Camboriú - Santa Catarina. In: ENCONTRO NACIONAL DO MIEIB, 25, 2009. Disponível em: http://www.mieib.org.br/wp-content/uploads/2017/06/MIEIB-Encontro-Nacional2009-Carta-de-Balnea\%CC\%8 1 rio-Camboriu\%CC\%8 1.pdf. Acesso em: 3 abr. 2018.

MOUFFE, Chantal. Por um modelo agnóstico de democracia. Revista de Sociologia e Política, Curitiba, 25, p. 11-23, nov. 2005. Disponível em: http://www.scielo.br/pdf/ rsocp/n25/31108.pdf Acesso em: 3 abr. 2018.

MUTZENBERG, Remo. Ações coletivas, movimentos sociais: aderências, conflitos e antagonismo social. 2002. 233f. Tese (Doutorado Sociologia) - Programa de Pós-Graduação em Sociologia, Universidade Federal de Pernambuco, Recife, 2002.

NUNES, Deise. O Movimento interfóruns de educação infantil: a construção de uma identidade cultural e política. In: REUNIÃO ANUAL DA ASSOCIAÇÃO NACIONAL DE PÓS-GRADUAÇÃO E PESQUISA EM EDUCAÇÃO, 33, 2010. Caxambu. Anais [...]. Anped: Caxambu, 2010.

P. 3. Entrevista. Recife (Pernambuco), 18 out. 2018.

P. 4. Entrevista. Recife (Pernambuco), 10 ago. 2018.

RANCIÈRE, Jacques. O desentendimento: política e filosofia. São Paulo: Editora 34, 1996. 
RODRIGUES, Cibele Maria Lima. Cultura política e Movimentos Sem-Teto: as lutas possíveis. 2009. Tese (Doutorado) - Programa de Pós-Graduação em Sociologia, Universidade Federal de Pernambuco, Recife, 2009.

ROSEMBERG, Fúlvia. $\bigcirc$ movimento de mulheres e a abertura política no Brasil: o caso da creche. Cadernos de Pesquisa, São Paulo, n. 51 . p. 73-79, 1984. (Texto apresentado na Reunião da IPSA (InternationalPolitical Science Association - Bulgaria).

SOUTHWELL, Myriam. "Con la democracia se come, se cura y se educa..." Disputas en torno a la transición y las posibilidades de una educación democrática. In: CAMOU, Antoni; TORTTI, Cristina e VIGUERA, Aníbal (coord.). La Argentina democrática: los años y los libros, Cidad Buenos Aires: Editora Prometeo, 2007.

SOUTHWELL, Myriam. Política y educación: ensayos sobre la fijación del significado. CRUZ, Ofelia; ECHEVARRIA, Laura (Coord.) El análisis político de discurso: usos y variaciones en la investigación educativa. México: Editora Juan Pablos; PAPDI, 2008.

SOUTHWELL, Myriam "Análisis político del discurso: posiciones y significaciones para la política educativa" In: Tello C. (Comp.). Política y epistemología de la investigación educativa. São Paulo: Mercado de Letras, 2012.

VIEIRA, Lívia Maria Fraga. A educação infantil e o Plano Nacional de Educação: as propostas da Conae 2010. Educação \& Sociedade, Campinas, v. 31 , n. 1 12, p. 809-831, jul./set. 2010

TELLES, Vera da Silva. Direitos sociais: afinal do que se trata? Belo Horizonte: Universidade Federal de Minas Gerais, 2006.

Ms. Karla Wanessa Carvalho de Almeida

Profa. Faculdade de Formação de Professores da Mata Sul e da Educação Básica Uaqueira e Joaquim Nabuco - Brasil)

Grupo de Pesquisa em Infância e Educação na Contemporaneidade: estudos interdisciplinares (CNPq) Orcid: https: / / orcid.org/0000-0002-5 197-1507 E-mail:wanessadeus@hotmail.com 
Artigo

O MIEIB e a política da educação infantil

Profa. Cibele Maria Lima Rodrigues

Fundação Joaquim Nabuco (Brasil)

Programa de Pós-Graduação em Educação, Culturas e Identidades

Grupo de Pesquisa em Infância e Educação na Contemporaneidade: Estudos Interdisciplinares

(CNPq)

Orcid: https: / / orcid.org/0000-0003-431 0-4216

E-mail: cibele.rodrigues@fundai.gov.br

Recebido 11 jan. 2020

Aceito 10 fev. 2020 